\title{
Molecular aspects of bladder cancer
}

\author{
Aspectos moleculares do câncer de bexiga \\ Gelbert Luiz Chamon do Carmo Amorim ${ }^{1}$, Denny Fabricio Magalhães Veloso ${ }^{1}$, José Carlos Vieira ${ }^{1}$ \\ Paulo Roberto Alves ${ }^{1}$
}

\begin{abstract}
One of the most important objectives of genetic markers of cancer will be the possible identification of individuals at greatest risk in order to allow better management and prognosis. Many urological tumors were associated to various types of gene alterations with a great number of genes involved in the process, hindering gene therapy. This treatment uses specific techniques and one or several genes are manipulated in the laboratory in order to induce molecular alterations that may block the oncogenic process. The article addresses these issues emphasizing the importance of the new molecular biology techniques.
\end{abstract}

Keywords: Urinary bladder neoplasms/genetics; Urinary bladder/ pathology

\section{RESUMO}

Um dos mais importantes objetivos dos marcadores genéticos para o câncer será a possível identificação do indivíduo com maior risco de doença, permitindo melhor conduta e prognóstico. Nos casos dos tumores urológicos, vários tumores têm sido relacionados a vários tipos de alterações genéticas, com um grande número de genes envolvidos, que dificulta muito a terapia gênica que é o processo no qual, por meio de técnicas específicas, gene ou genes são manipulados em laboratório para provocar alterações moleculares capazes de bloquear o processo oncogênico. 0 presente artigo aborda essas questões enfatizando a importância do advento das novas técnicas de biologia molecular.

Descritores: Neoplasias da bexiga urinária/genética; Bexiga urinária/ patologia

\section{INTRODUCTION}

The importance of genetics greatly increased in the past years and its study has become necessary to understand several diseases ${ }^{(1)}$. Biological processes have some genetic influence; investigating their determining molecular mechanisms is the object of numerous approaches, possibly due to the development of technologies allowing the study of DNA.

Despite the progress of surgical techniques, effective treatment still requires understanding the phenomena that determine cancer.

Genetic and environmental factors are causes of genome lesions leading to cancer, a genetic disease at somatic level resulting from sequential mutations in genes responsible for cell proliferation, death and differentiation, resulting in genomic instability.

Therefore, the cell where the cascade of mutations was initiated starts multiplying, evolving in sublineages with varied grades of abnormalities and malignancy and generating tumor heterogeneity.

Some of the mechanisms affecting the normal sequence of cell cycle involve mutations in two groups of genes, the oncogenes that are related to the induction of cell division and the tumor suppressor genes that act in oncogenes in proliferation control.

Mutations in suppressor genes can lead to malignant transformation of cells when the allele function is lost, thus causing uncontrolled cell division, abnormal differentiation and deficient apoptosis.

The gene most frequently mutated in different types of cancer in humans, including bladder tumors, is the protein $\mathrm{p} 53^{(2)}$.

Chromosome instability must be considered in tumor cells, suggesting that cancer could be the result of an imbalance in number of chromosomes, therefore, in the amount of functional genetic information in the cell.

There is still a marked variation in susceptibility to carcinogens among individuals; likewise, several genetically determined factors seem to be related to the risk of cancer, without a correlation with carcinogens. Exogenous factors, such as lifestyle, can determine the

\footnotetext{
Study carried out at Santa Casa de Belo Horizonte (MG), Brazil.

' Department of Urology, Santa Casa de Belo Horizonte (MG), Brazil.

Correspondence to: Gelbert Luiz Chamon do Carmo Amorim - Rua: Manaus, 645 - Santa Efigênia - CEP: 30150-350 - Belo Horizonte - Minas Gerais (MG), Brazil. Tel.: (31) 37747500 -

e-mail: gelbertchamon@hotmail.com

Received: Jan 13, 2010 - Accepted: Dec 20, 2010
} 
intake of vitamins, antioxidants and compounds that modulate the risk of developing neoplasms.

One of the most important objectives of genetic markers of cancer will be possible identification of individuals at higher risk of developing the disease, allowing better management and prognosis.

Several urological tumors were associated to various types of genetic abnormalities, with a large number of genes involved, which hinders gene therapy.

Gene therapy is the process in which one or more genes are manipulated in a laboratory by specific techniques to cause molecular changes that are able to block the oncogenic process.

\section{BLADDER CANCER}

Bladder cancer, especially transitional cell carcinoma (TCC), is the fourth most common tumor in males, in the United States. This cancer has a variable clinical course and prognosis, and $70 \%$ presenting as a superficial tumor upon diagnosis. However, over $60 \%$ of patients have recurrence after endoscopic resection, and a major concern is that in $30 \%$ of them it will occur in a more advance grade and/or stage, showing disease progression. About 5\% to10\% of patients with initially superficial tumors will develop invasive disease with involvement of bladder muscles ${ }^{(3-7)}$.

Among patients with radically treated local invasive disease, $50 \%$ will develop metastatic disease. Several prognostic markers have been studied to predict which superficial tumors would become invasive and which invasive tumors tend to produce metastases.

\section{Gene p53}

Upon development of DNA analysis, by means of cloning techniques, a large number of genes were found to be involved in the onset and progression of several types of cancer.

Special importance has been given to mutations in the suppressor gene $p 53$, considered to be the most studied genetic defect in bladder cancer ${ }^{(2)}$.

This gene, located in the short arm of chromosome 17 , seems to act in encoding a nuclear protein of $53 \mathrm{kDa}$, which has an effect in transcriptional regulation of cell cycle. Mutations of $p 53$ cause increased expression and half-life of this non-functioning protein, with consequent loss of its suppressing activity, so that this is now detected by immunohistochemistry.

Detection of nuclear accumulation of protein $p 53$ by immunohistochemistry is strongly associated to $p 53$ mutations; however, the absence of immunoreactivity does not exclude this genetic abnormality. Reactivity of this protein was demonstrated in $50 \%$ of patients with bladder cancer (TCC), specially in high grade and advanced stage tumors. Higher occurrence of mutations in $p 53$ was also demonstrated in invasive tumors when compared to superficial ones. Fujimoto et al. ${ }^{(8)}$ found mutant $p 53$ in $50 \%$ of patients with invasive tumors and only $7.6 \%$ in superficial tumors.

Several authors studied p53abnormalities and observed a direct relation between the occurrence of genetic abnormalities and the chances of disease progression and death.

Observation of mutations in superficial tumors was reported in $22 \%$ to $64 \%$ of patients, with a direct relation between likelihood of recurrence and decreased survival. Hudson et al. demonstrated $71 \%$ of progression to invasive disease in $p 53$ positive patients compared to $22 \%$ in patients with undetectable protein ${ }^{(9)}$.

Another important factor is decreased survival related to disease in patients treated by radical cystectomy due to localized disease who present increased $p 53$ expression, demonstrating it is an important indicator, regardless of the grade and stage of the disease.

It is known that superficial recurrences usually occur with diploid tumors and negative $p 53$ mutants and tumors with metastases are aneuploid and $p 53$-positive, but both have no prognostic advantages considering cell proliferation rates.

In regard to carcinoma in situ, a strong associated was observed between increased expression of $p 53$ expression and chances of disease progression and decreased disease-specific survival. In this analysis, $48 \%$ showed increased $p 53$ expression and $86.7 \%$ of them progressed.

More recently, some authors demonstrated that p53 positivity can be converted after immunotherapy with BCG; therefore, it was also demonstrated that the likelihood of disease progression would be higher when failure to BCG treatment occurs. In p53-negative patients, approximately $20 \%$ presented disease progression.

By and large, we observe that p53 expression is directly related to prognosis of patients with bladder cancer (TCC), and those with superficial disease and increased $p 53$ expression must be carefully followed up. Patients with carcinoma in situ treated with BCG who relapse and have positive $p 53$ must be considered candidates to radical cystectomy.

Those who underwent radical cystectomy and have positive $p 53$ should be considered as at higher risk for progression, with a strict control.

It is worth mentioning that the immunohistochemical expression of gene $p 53$ does not change the importance of traditional prognostic factors of bladder cancer, especially the histological grade of cancer. Additionally, there are conflicting data in the literature when analyzing 
the role of gene $p 53$ expression as an independent factor in prognosis of bladder carcinomas.

A possible explanation for the conflicting results about this gene would be difficult standardization of different techniques to detect gene $p 53$ mutations, since none of them has $100 \%$ sensitivity.

Another explanation for the controversies would be the different expression of several antibodies, if compared to antibody pab 1801, which present poorer results in detection of mutations in tissues fixed in formalin. On the other hand, agreement of pab 1801 in fresh specimen and paraffin-treated material is approximately 92 to $96 \%$. However, when comparing three antibodies - CM1, Pab 1801 and D07 - in fresh material and in paraffin, it was observed that the main disagreement factor is the variable expression of protein p53 in the same tumor sample, regardless of the antibody used.

Hence, the relation between the several agents acting in tumor biology should be better understood, and the detection techniques should be improved and standardized to determine the clinical role of gene $p 53$ expression $^{(10,11)}$.

\section{GENOMIC INSTABILITY}

Genomic instability, particularly in transitional cell carcinoma of the bladder with two types, is detected in six out of 200 cases of TCC. Genomic instability in cancer could be divided into two types: microsatellite instability (MSI) and microsome instability (CIN). MSI is related to defects in mismatch repair (MMR) and CIN is related to abnormalities in chromosome segregation.

Considering bladder cancer, $50 \%$ is related to CIN and presents worse prognosis and $9 \%$ is characterized as MSI with better prognosis; moreover, bladder cancer associated to MSI is more frequent in young patients ${ }^{(12-17)}$.

\section{GSTM1 AND CYP2D6}

Susceptibility to bladder cancer depends on the correlation between genetic factors and the environment. Recent researches aimed at associations of susceptibility to bladder cancer and variance in polymorphism of genes CYP2D6 and GSTM1 ${ }^{(18)}$.

Gene CYP2D6 is related to cytochrome P450 whose substrata include aromatic amines and nitrosamines of tobacco.

GSTM1 is related to enzymes with several functions, including deintoxication of the aromatic cycle of hydrocarbons of cigarettes and aromatic amines.

Some studies carried out in patients with bladder cancer analyzed the occurrence of both genes and showed that the gene GSTM1 is more associated to the occurrence of bladder cancer, especially in those patients with superficial tumors and the association is stronger in smokers.

Gene CYP2D6 did not present the same significance of association.

\section{Amplification/over-expression of a mitotic gene in bladder cancer}

Genomic instability has been suggested as a cause of malignant transformation and progression to cancer; some studies indicate that several genetic instabilities are associated to different mechanisms leading to human cancer.

The best characterized genomic instability is inactivation of gene-repairing DNA; however, this mode of instability can be verified in a small proportion of tumors.

Gene STK15/BTAK/AuroraA is associated with aneuploidy and transformation when overexpressed in cells; when this occurs there is activation of an oncogen involving the amplification of a centrometer and resulting in miscegenation of chromosomes. This aneuploidy, when added to prognostic clinical factors is associated to bladder tumor.

Although high expression of STK15 seems to be frequent in bladder tumors, approximately $30 \%$ of aneuploidy in aggressive bladder tumors does not evidence STK15 with overexpression. This suggests that, in a fraction of bladder tumors, other genes are associated to aneuploidy. In fact, two discoveries of members of the Aurora kinase family, Aurora-B and Aurora-C, were reported as responsible for the increased expression of some human cancers.

It is important to note that STK15 is located in chromosome 20q13 and it was identified by the search of sequences with over-expression in chromosome 20 . The $20 \mathrm{q}$ region is typically amplified in high grade bladder cancer.

Therefore, while analyzing the occurrence of genomic instability, especially in regard to aneuploidy and the occurrence of bladder tumors, it is observed that they are strongly related.

Tumors with a minimum deviation of chromosome copy are clinically less aggressive than those with more deviation of chromosome copies.

Recent investigations showed that STK15/BTAK/ AuroraA is involved in the regulation of centrometer and it is linked to frequent amplification and overexpression of human tumors and, therefore, it would be a regulating component of chromosome segregation, and it can cause aneuploidy and transformation.

Hence, it is confirmed that STK15 is associated to increased expression of mitoses and aneuploidy, 
and consequently more aggressive feature of bladder cancer ${ }^{(19)}$.

\section{Loss of chromosome 3 allele, microsatellite abnormalities and bladder cancer}

Studies indicated that deletions in chromosome 3, especially three discreet ones in regions $3 p$ are identified in bladder cancer, suggesting that the gene suppressor is in these regions. Detection of the loss of alleles in these regions would also be associated to higher severity of bladder tumor, suggesting its relation with cancer progression.

Other studies indicated that allele loss could occur in chromosomes 17p13, 3p25-26,9q32-33. Higher occurrence of allele deletion is in chromosome $9 p$ and 9q; molecular maps showeddseveral suppressing genes in chromosome 9 and higher likelihood of loss of chromosome 9 would be an early event in onset of cancer. The other genetic abnormalities that frequently occur are located in chromosomes 1, 8, 16,14 and 21. Thus, loss of alleles in multiple sites of the genoma frequently occurs in bladder cancer.

Upon isolate analysis of carcinoma in situ patients, it was observed that this type of tumor contains cells with non-specific loss of chromosome 9; however, neoplasm in situ with synchronous carcinoma showed lesions with loss in chromosome 9. Mutations in p53 precede the losses of alleles in chromosome 9, and 9 p21 in in situ carcinoma is a precursor of bladder cancer invasiveness, whereas non-invasive carcinomas where chromosome 9 with losses (9p11-9q12) are early and frequently combined to homozygotic deletions of $9 \mathrm{p} 21^{(20)}$.

\section{Hyperamplification of centrometer as a predictive factor in progression and recurrence of bladder cancer}

Several pieces of evidence suggest that overexpression of STK15/BTAK/AuroraA, a gene located in 20q13, induces aneuploidy, microsome instability and centrometer amplification $(\mathrm{CH})$. Data suggest that there is a strong association between $\mathrm{CH}$ and overexpression of Aurora-A. A large number of copies of 20q13 would be associated to several fractions of chromosomes 7, 9 and 17 , as well as $\mathrm{CH}$. It is suspected that half of the cases of $\mathrm{CH}$ could be caused by amplification or gain of gene STK15/BTAK/AuroraA.

Recentstudies demonstrated that hyperamplification of centrometer $(\mathrm{CH})$ goes along with chromosome instability during the development of bladder cancer, which confers the tumors increased characteristics of malignancy; therefore, it would be an independent and important prognostic factor for the recurrence of cancer; however, when progression of bladder cancer is analyzed, it is still not possible to conclude that $\mathrm{CH}$ could influence its occurrence.

\section{CONCLUSION}

With theemergenceofnewmolecularbiologytechniques, cell abnormalities occurred in carcinogenesis could be studied in more details. Nowadays, as a general concept, it is accepted that the carcinogenic process results from a complex path involving the combination of inactivation of tumor-inhibiting genes and activation of tumor-promoting genes (oncogenes). Several stages must be reached in the formation of a tumor, starting with tumor inhibition, then proliferation, loss of inhibition by contact, invasion and metastasis of the cancer cell.

Accumulation of mutations in essential genes can transform a normal cell into a cancer cell. This transformed cell then grows in a disorganized manner until it forms the tumor with additional mutations occurring during this process. When cancer is diagnosed, it is a mix of cancer cells with subclones, making it difficult to establish the order of occurrence of genetic abnormalities.

Bladder cancer, however, allows a different and unique study of mutations because the different tumor subclones grow in separate sites and allow independent studies.

Several studies were and are being carried out in an attempt to relate the biological characteristics of bladder cancer, its occurrence, histology and its severity with the different types of mutations and chromosome instability.

It should be kept in mind that molecular biology and genetics are in the path to new knowledge about tumor molecular pathophysiology and that gene therapy stopped being fiction to be transformed in a real hope.

\section{REFERENCES}

1. Gattás N. Terapia gênica: 0 urologista de olho no futuro: Sinopse de Urologia [Internet] 1998 [citado 2010 Jan 20]; 2(5). Disponível em: http://www. uronline.unifesp.br/uronline/ed1098/terapia.htm

2. Almeida SHM, Derrose D, Freitas MA, Liboni M, Dinardi R, Moreira H. Marcadores em Câncer de bexiga - importância da expressão do p53 como indicador prognóstico. Braz J Urol. 2000;26:378-384.

3. Yoshiaki Y, Hideyasu M, Tomoko F, Atsunori O, Saturo Y, Masaru O, Higeto K, Kohsuke S, Katsusuke N. Centrossome hyper amplification predicts progression and tumor recurrence in bladder cancer. Clin Cancer Res. 2004;10(19): 6449-55.

4. Yamamoto $Y$, Matsuyama $H$, Kawauchi $S$, Furuya T, Liu XP, Ikemoto $K$, et al. Biological characteristics in bladder cancer depend on the type of genetic instability. Clin Cancer Res. 2006;12(19):2752-8. 
5. van Tilborg AA, de Vries A, de Bont M, Groenfeld LE, van der Kwast TH,Zwarthoff EC. Molecular evolution of multiple recurrent cancers of the bladder. Hum Mol Genet. 2000;9(20):2973-80.

6. Hoque MO, Lee CC, Cairns P, Schoenberg M, Sidransky D. Genome-wide genetic characterization of bladder cancer: a comparison of high-density single-nucleotide polymorphism arrays and PCR-based microsatellite analysis. Cancer Res. 2003; 63(9):2216-22.

7. Cafe $L E$, Arruda H. Novos marcadores no câncer de bexiga. Sinopse Urol. 1999;1(1): 3-4.

8. Fujimoto K, Yamada Y, Okajima E, Kakizoe T, Sasaki H, Sugimura T, Terada M. Frequent association of p53 gene mutation in invasive bladder cancer. Cancer Res. 1992;52(6):1393-8.

9. Hudson MA, Humphrey PA, Swanson PE, Wick MR, Vollmer RT. Use of p53, MIB-1, EGFR, c-erb B-2, bcl-2 as prognostic markers in bladder cancer patients. Proc Am Urol Assoc. 1996; 155(Suppl A): 615A.

10. Li M, Zhang ZF, Reuter VE, Cordon-Cardo C. Chromosome 3 allelic losses and micro satellite alterations in transitional cell carcinoma of the urinary bladder: Am J Pathol. 2006;149(1):229-35.

11. Halachmi S, Madeb R ,Kravtsov A, Moskovitz B, HalachmiN, Nativ 0. Bladder cancer-genetic overview. Med Sci Monit. 2001;7(1):164-8.

12. Turyn J,Matuszewski M,Schlichtholz B. Genomic instability analysis of urine sediment versus tumor tissue in transitional cell carcinoma of urinary bladder. Oncol Rep. 2006;15(1):259-65.
13. Hopman AH, Kamps MA, Speel EJ, Schapers RF, Sauter G, Ramaekers FC. Identification of chromosome 9 alterations and p53 accumulation in isolated carcinoma in situ of the urinary bladder versus carcinoma in situ associated with carcinoma. Am J Pathol. 2002;161(4):1119-25.

14. Cheng L, Gu J, Ulbright TM, MacLennan GT, Sweeney CJ, Zhang S, et al. Precise microdissection of humam bladder carcinomas reveals divergent tumor subclones in the same tumor. Cancer 2002;94(1):104-10.

15. Matsuda H, Uejima S, Kurita T. [Microsatellite instability in renal cell carcinoma and bladder tumors]. Hinyokika Kiyo. 1996;42(1):27-31. Japanese

16. Catto JW, Meuth M, Hamdy FC. Genetic instability and transitional cell carcinoma of the bladder. BJU Int. 2004;93(1):19-24.

17. Erill N, Colomer A, Verdú M, Román R, Condom E, Hannaoui N, Banús JM, Cordon-Cardo C, Puig X. Genetic and inmunophenotype analyses of TP53 in bladder cancer: TP53 alterations are associated with tumor progression. Diagn Mol Pathol. 2004;13(4):217-23.

18. Figueiredo AJ, Coimbra HB, Sobral FT, Martins J, Linhares-Furtado AJ, Regateiro FJ. Genetic polymorphisms of genes GSTM1 and CYP2D6 and bladder cancer. Braz J Urol. 2000;I26(3): 250-5.

19. Sen S, Zhou H, Zhang RD, Yoon DS, Vakar-Lopez F, Ito S, et al. Amplification/ overexpression of a mitotic kinase gene in human bladder cancer. $\mathrm{J}$ Natl Cancer Inst. 2002 94(17):1320-9.

20. Li M, Zhang ZF, Reuter VE, Cordon-Cardo C. Chromosome 3 allelic losses and microsatellite alterations in transitional cell carcinoma of urinary bladder. Am J Pathol. 1996;149(1):229-35. 